\author{
SERIES "RECENT DEVELOPMENTS IN PULMONARY INFECTIONS" \\ Edited by M. Woodhead and T. Schaberg \\ Number 9 in this Series
}

\title{
Pneumococcal vaccination: current and future issues
}

\author{
Å. Örtqvist
}

\begin{abstract}
Pneumococcal vaccination: current and future issues. A.Örtqvist. (C)ERS Journals Ltd 2001.

ABSTRACT: Infection with Streptococcus pneumoniae remains a major global health burden meaning the development of effective vaccines is urgently needed. The current 23-valent polysaccharide vaccine has been shown to prevent pneumococcal pneumonia in immunocompetent young adults, but not in elderly persons.

However, in prevention of invasive pneumococcal disease, the vaccine is efficacious in the elderly and may also be effective in some groups of immunocompromised patients. The polysaccharide vaccine is, therefore, recommended in all older ( $\geqslant 55-65$ yrs of age) adults and in young children ( $>2$ yrs of age) who have a high risk for pneumococcal disease. Revaccination can be safely performed and is recommended 5 yrs after the first dose.

In children $<2$ yrs of age, the new polysaccharide-protein conjugate vaccines, including 7-11 serotypes, seem to be effective in the prevention of invasive disease, severe pneumonia and serotype-specific (and vaccine-related types) otitis media. The low serotype coverage, need for repeated doses, and high price, may decrease the usefulness of the new conjugates. However, the included serotypes correspond to those most often associated with penicillin resistance and vaccination is, therefore, a possible tool in limiting the spread of antibiotic-resistant pneumococci. Eur Respir J 2001; 18: 184-195.
\end{abstract}

Karolinska Institutet and Dept of Infectious Diseases, Karolinska Hospital, Stockholm, Sweden.

Correspondence: Å. Örtqvist, Dept of Infectious Diseases, Karolinska Institutet, Karolinska Hospital, SE-17176, Stockholm, Sweden. Fax: 46851771804

Keywords: Conjugate vaccines polysaccharide revaccination

Streptococcus pneumoniae vaccination

Received: August 92000

Accepted after revision October 32000
Infection with Streptococcus pneumoniae remains a major cause of morbidity and mortality in all age groups, being the most common cause of otitis media, community-acquired bacterial pneumonia, and bacterial meningitis $[1,2]$. The burden of disease is greatest among young children and the elderly. Although the exact incidence is not known, it has been estimated that pneumococcal pneumonia causes at least 1 million deaths yearly in children $<5$ yrs of age, with most occurring in the developing world [3]. Severe pneumococcal infections are most often the result of dissemination of bacteria to the bloodstream, the central nervous system, or other normally sterile sites. The incidence of such "invasive pneumococcal disease" has been estimated at 15-30 per 100,000 inhabitants per year in developed countries, with the highest rates among persons $\geqslant 65 \mathrm{yrs}$ of age $(\geqslant 50 /$ $100,000)$ and children aged $\leqslant 2$ yrs $(>150 / 100,000)$ $[1,4]$. Being based mostly on blood cultures, these figures are likely to be an underestimation of the true incidence of invasive pneumococcal disease, since they do not take into account persons from whom blood cultures were never obtained or those where the culture was performed after the start of antibiotic therapy [5]. In adults, pneumococcal bacteraemia is associated with pneumonia in $60-85 \%$, meningitis $5-10 \%$ and no focal infection in $5-10 \%$ of the cases, respectively, while in young children the most frequent finding is bacteraemia without focal signs of infection $[1,6,7]$. Despite appropriate antibiotic therapy and intensive care treatment, there is a considerable casefatality in pneumococcal bacteraemia, 15-20\% among the adults overall, with the highest rates among the elderly and patients with severe underlying medical conditions $[1,4,7]$. Thus, pneumococcal diseases are a major public health problem all over the world, a problem underlined by the rapidly spreading antimicrobial resistance to common and essential antibiotics.

Previous articles in this series: No. 1: Hammerschlag MR. Chlamydia pneumoniae and the lung. Eur Respir J 2000; 16: 1001-1007. No. 2: Ewig S, Schäfer H, Torres A. Severity assessment in community-acquired pneumonia. Eur Respir J 2000; 16: 1193-1201. No. 3: Nicod LP, Pache J-C, Howarth N. Fungal infections in transplant recipients. Eur Respir J 2001; 17: 133-140. No. 4: Jones AM, Dodd ME, Webb AK. Burkholderia cepacia: current clinical issues, environmental controversies and ethical dilemmas. Eur Respir J 2001; 17: 295-301. No. 5: Rook GAW, Seah G, Ustianowski A. M. tuberculosis: immunology and vaccination. Eur Respir J 2001; 17: 537-557. No. 6: Ioanas M, Ferrer R, Angrill J, Ferrer M, Torres A. Microbial investigation in ventilator-associated pneumonia. Eur Respir J 2001; 17: 791-801. No. 7: Wilson R. Bacteria, antibiotics and COPD. Eur Respir J 2001; 17: 995-1007. No. 8: Stephenson I, Nicholson KG. Influenza: vaccination and treatment. Eur Respir J 2001; 17: 1282-1293. 
At the moment, vaccination is the only available tool to prevent disease caused by $S$. pneumoniae.

\section{Pneumococcal vaccines}

There are currently two established approaches to pneumococcal vaccination: capsular polysaccharide vaccines and protein-polysaccharide conjugate vaccines. Of these, the polysaccharide vaccine has been available for $>15$ yrs and for several different conjugate vaccines, clinical trials have recently finished or are ongoing. One hepatvalent conjugate vaccine has recently been licensed in some countries. In addition, there is active research for improved vaccine formulations. The research area is extensive, but includes evaluation of possible adjuvants to the polysaccharide or conjugate vaccines and of different protein antigens common to all pneumococcal serotypes, as potential vaccine candidates.

\section{Capsular polysaccharide vaccines}

Vaccine development. A pneumococcal vaccine, a crude whole-cell vaccine, was developed for the first time in 1911, 30 yrs after the isolation of $S$. pneumoniae [8]. During the next $30 \mathrm{yrs}$, with the realization that the pneumococcus consisted of different capsular serotypes, several studies with single type-specific vaccines were performed. Based on studies with vaccines including two to four serotypes, two hexavalent vaccines were marketed at the end of the 1940s. These vaccines, however, were on the market only for a few years because, at approximately the same time, antibiotics that were highly effective against pneumococci became available, leading to a significantly reduced mortality in pneumococcal disease and a general belief that vaccines were no longer necessary. In 1964, Austrian and Gold [9] demonstrated that this belief was false, reporting that case-fatality rates in pneumococcal bacteraemia were still very high despite adequate antibiotic therapy. In their 10-yr study from a large hospital in New York, $\sim 25 \%$ of all patients with bacteraemia, and nearly half of those aged $\geqslant 60 \mathrm{yrs}$, died. Their findings revived the interest in pneumococcal vaccines, and in 1977 a polysacccharide vaccine including 14 capsular serotypes (14-valent) was licensed for use in the USA. In 1983, this vaccine was replaced by the current 23 -valent vaccine. The 23 -valent vaccine includes $25 \mu \mathrm{g}$ purified capsular polysaccharide antigens from each of 23 serotypes (serotypes 1, 2, 3, 4, 5, 6B, 7F, 8, 9N, 9V, 10A, 11A, $12 \mathrm{~F}, 14,15 \mathrm{~B}, 17 \mathrm{~F}, 18 \mathrm{C}, 19 \mathrm{~A}, 19 \mathrm{~F}, 20,22 \mathrm{~F}, 23 \mathrm{~F}$, and $33 \mathrm{~F}$ ) that represent $\sim 90 \%$ of all serotypes that cause invasive pneumococcal disease [1].

Immunogenicity. To date, 90 different serotypes of $S$. pneumoniae have been described, based on antigenic differences of the capsular polysaccharide [10]. These antigens induce type-specific antibodies that enhance opsonization, phagocytosis and killing of pneumococci by phagocytic cells [1]. Polysaccharide antigens induce antibodies primarily by a T-cell-independent mechanism, meaning that children $<2$ yrs of age do not respond or respond poorly to vaccination because of their immature immune system. Otherwise, vaccination in general induces a two-fold or greater rise of serotype-specific antibody within 2-3 weeks [11]. The antibody response is also satisfactory in most elderly persons $[12,13]$, but a subset of those may respond only to some of the 23 serotypes included in the vaccine [ 14 , 15]. Furthermore, the functional activity (opsonophagocytosis and/or avidity) of postvaccination antibodies may be lower in elderly than in younger persons, even at similar levels of antibody titres [16]. Thus, it is not surprising that it has not been possible to clearly define a "protective level" of pneumococcal antibodies [1]. In immunocompromised patients, the antibody response is often low or even absent, while persons $\geqslant 2$ yrs of age with anatomical or functional asplenia, or chronic diseases such as chronic obstructive pulmonary disease (COPD) or diabetes mellitus, generally respond with levels comparable to those observed in healthy persons.

Vaccine efficacy and effectiveness. There are two major obstacles when trying to determine the efficacy of the polysaccharide vaccine. Firstly, the lack of sensitive and specific diagnostic methods for establishing the diagnosis of pneumococcal pneumonia makes this an unreliable end-point. However, since $S$. pneumoniae is the major cause of community-acquired pneumonia, this problem, which of course applies to prospective, randomized studies, as well as to case-control or indirect cohort studies, may be partly overcome by using radiographically confirmed pneumonia as an end-point. However, this, will require a much larger sample size or a study population with a very high risk for pneumococcal disease [17].

Secondly, because of the relatively low incidence of invasive pneumococcal disease, a very large study population will be required if this should be the endpoint of a prospective study [18]. However, this obstacle may be overcome by the use of case-control or indirect cohort studies [19, 20].

Thus, it is not surprising that the question of the efficacy of the polysaccharide vaccine in prevention of pneumococcal pneumonia in those who need it most today (the elderly) remains unresolved, while it has been convincingly shown that the vaccine prevents against invasive pneumococcal disease in adults, including the elderly.

Pneumococcal pneumonia. Before the license of the 14-valent vaccine, two randomized, controlled trials demonstrated a significant protective efficacy of multivalent vaccines against pneumococcal pneumonia and radiographically confirmed pneumonia among 9,000 young, healthy, novice gold-miners in South Africa [21, 22]. In another prelicense study, performed with a 14-valent vaccine and including $\sim 12,000$ persons $\geqslant 10$ yrs of age from Papua New Guinea, the risk for pneumonia overall was the same in the vaccine as in the placebo group, but there were significantly fewer pneumonia deaths among those who were vaccinated [23].

Since the license of the 14-valent vaccine, five large 
studies have been performed in elderly persons. The results have been conflicting, with two in favour of the vaccine [24, 25] and three showing no difference between the pneumococcal vaccine group and the control group [17, 26, 27]. Different approaches, for example, the choice of study population, if the study was placebo-controlled or not, and if so, the choice of placebo, have been used in these five studies, making the results difficult to compare. The study by GAILLAT et al. [24], which included 1,686 elderly persons from $\sim 50$ French geriatric hospitals or homes for the elderly, used the 14-valent vaccine and was randomized, but was not placebo-controlled or blinded. In addition, the few cases of pneumonia during the study period indicated either an uncommonly low incidence $(2 \%)$ for that population, or a low detection rate.

An American study by SIMBERKofF et al. [26] included $\sim 2,300$ ambulatory patients at Veterans Administration hospitals, who were $>55$ yrs of age and had an increased risk for pneumococcal disease. The power of this study was lowered by an unexpectedly low incidence of pneumococcal pneumonia (all types), 0.4\% instead of a calculated annual rate of $1 \%$.

Two Finnish studies have used the approach of giving pneumococcal vaccine plus influenza vaccine to the vaccine group and influenza vaccine only to the control group. The first study by KoIvula et al. [25] was performed during the first half of the 1980s, but took $>10$ yrs to publish. In this study, using the 14valent vaccine in $\sim 2,800$ persons $\geqslant 60 \mathrm{yrs}$ of age recruited from the community, no significant protection was found against pneumococcal pneumonia, $15 \%(95 \%$ confidence interval (CI), $-43-50 \%)$. There was a protective efficacy of $56 \%(95 \% \mathrm{CI}, 3-80 \%)$ in a subgroup of persons with a high risk for developing pneumonia, but the CI was wide, almost reaching zero, and the efficacy in the low-risk group was nearly the opposite, $-66 \%(95 \%$ CI, $-257-23 \%)$. For pneumonia overall, no protection could be demonstrated, either for the group as a whole or for any of the subgroups. The second Finnish study used the 23valent vaccine and included nearly 27,000 persons $\geqslant 65$ yrs of age in Northern Finland in 1992-3 [27]. During the follow-up period of 38,037 person-yrs, there were 261 cases of radiographically verified pneumonia (83\% admitted to hospital) and $35 \%$ of those were diagnosed as pneumococcal pneumonia, mostly by serology. Since influenza is a major risk factor for pneumonia, the inclusion of influenza vaccination in both groups may have left less room for protection by the pneumococcal vaccine. The results were, therefore, presented as the "incremental" effectiveness of the pneumococcal vaccine given simultaneously with the influenza vaccine over influenza vaccine given alone during the influenza season. As can be seen in table 1, no protection against pneumococcal pneumonia or pneumonia overall could be demonstrated. In addition, a subanalysis performed outside the influenza season, showed that the relative risk for pneumococcal pneumonia or pneumonia overall was similar, with no difference between the two groups.

ÖRTQVIST et al. [17] performed a multicentre, randomized, placebo-controlled, blinded study of the 23-valent vaccine in 693 persons, $50-85$ yrs of age, who had a history of previous admittance to hospital because of community-acquired pneumonia. Using a Cox regression analysis, no difference could be demonstrated for the primary end-points, pneumonia overall and pneumococcal pneumonia, between the two groups during a total follow-up period of $\sim 800$ person-yrs. The incidence of diagnosed pneumococcal pneumonia in this population was lower than the pretrial calculations, which somewhat lowered the power of the study. However, the assumption that $S$. pneumoniae cause $\geqslant 50 \%$ of all community-acquired pneumonia in the elderly is also likely to have been true for the patients in that study, and is supported by the fact that pneumococci was the causative agent in $60 \%$ of those with an established aetiological diagnosis. Therefore, it is likely that only a very limited protective efficacy would have been demonstrated in this patient group. Middle-aged and elderly persons with a high risk for pneumonia are, of course, groups where effective vaccines are the needed most, but these results [17] may not be applicable to the general population of the same age. Although overtly immunocompromised patients were not included, the higher risk of pneumonia in patients who had already been hospitalized for this disease [28] may, in some cases, have been due to a partially deficient general or local immune defence and a poorer response to vaccination. To analyse this further, the magnitude (geometric means) of postvaccination antibody titres and antibody pre-post vaccination increases have been compared in patients from the vaccination study who developed a new pneumonia with those without recurrences [29]. The type-specific antibodies to types $1,4,14,18 \mathrm{C}, 19 \mathrm{~F}$, and the combined geometric mean antibody titre of these five antigens were measured and it was found that patients who responded to the combined antigens with an antibody fold increase of $\geqslant 4$, or a high postvaccination antibody titre

Table 1. - Outcome rates per 1000 person·yrs, relative risk and incremental effectiveness of vaccine versus control group

\begin{tabular}{|c|c|c|c|c|c|c|}
\hline & \multicolumn{2}{|c|}{ Vaccine group* } & \multicolumn{2}{|c|}{ Control group } & \multirow{2}{*}{$\begin{array}{l}\text { Relative risk } \\
\quad(95 \% \mathrm{CI})\end{array}$} & \multirow{2}{*}{$\begin{array}{l}\text { Incremental effectiveness } \\
(95 \% \mathrm{CI})\end{array}$} \\
\hline & $\mathrm{n}$ & Rate $\cdot 1000 \cdot \mathrm{yr}^{-1}$ & $\mathrm{n}$ & Rate $1000 \cdot \mathrm{yr}^{-1}$ & & \\
\hline Pneumonia & 145 & 7.4 & 116 & 6.3 & $1.2(0.9-1.5)$ & $-20(-50-10)$ \\
\hline Pneumococcal pneumonia & 52 & 2.7 & 40 & 2.4 & $1.2(0.8-1.9)$ & $-20(-90-20)$ \\
\hline Pneumococcal bacteraemia & 2 & 0.06 & 5 & 0.17 & $0.4(0.1-1.9)$ & $+60(-40-90)$ \\
\hline
\end{tabular}

Adapted from [27]. CI: confidence interval. *: pneumococcal + influenzae vaccines; ${ }^{*}$ : influenzae vaccine only. 
$\left(>12 \mu \mathrm{g} \cdot \mathrm{mL}^{-1}\right)$, had a significantly lower risk for recurrent pneumonia than poor responders.

In summary, the results of prospective trials in the elderly are inconclusive as they do not clearly show that the pneumococcal vaccine is efficacious in the prevention of pneumococcal pneumonia, nor convincingly demonstrate a lack of protection. This conclusion is also supported by two meta-analyses, although they are both somewhat limited as they only include studies published before 1987 [30, 31].

Performing cohort studies including high-risk subjects with a high event rate is one way to increase the power of vaccination studies. Recently, a 2-yr retrospective cohort study assessing the health effects in elderly persons with chronic lung diseases was published [32]. The authors studied a cohort of members of a managed care organization who were $\geqslant 65$-yrs-old and had a diagnosis of chronic lung disease. Out of the 1,898 subjects of the cohort, those who had received a pneumococcal vaccination $(67 \%)$ were compared with unvaccinated subjects for two outcomes, hospitalizations for pneumonia or influenza, and deaths all causes. A multivariate model was used to control for covariates and potential confounders. Pneumococcal vaccination was found to be associated with a significantly lower risk for pneumonia and influenza hospitalizations, relative risk (RR) 0.57 (95\% CI 0.38-0.84), and death, RR 0.71 (95\% CI $0.56-0.91)$. Although interesting, this study has severe limitations. Some of these were appropriately pointed out by the authors and include significant differences in baseline characteristics between the two study groups. The unvaccinated subjects were older and had significantly more comorbid conditions such as heart disease, stroke/dementia, cancer, liver disease and a history of pneumonia. Further, only $56 \%$ of the unvaccinated group received influenza vaccination compared to $\sim 80 \%$ of those who had been vaccinated with the pneumococcal vaccine. This is crucial since influenza vaccination alone has been shown to reduce the need for hospitalization due to influenza and pneumonia and lower the risk of death [33-36]. What the authors do not comment upon is why hospitalization for influenza was included as an end-point in a pneumococcal vaccine study. In total, there were 174 hospitalizations (it is not evident whether subjects were admitted more than once) for pneumonia or influenza during the 2-yr outcome period. It is not stated how many of these were caused by influenza. Neither is the absolute number of patients hospitalized for pneumonia stated, or the RR for this occurrence outside the influenza season. Even when using multivariate statistical methods it is difficult to see how the effects of influenza and pneumococcal vaccination could be separated, without at least analysing the outcome during the influenza-free period.

Large-scale intervention studies are another way of addressing the problem of power in vaccination trials. In Stockholm County, Sweden, a 3-yr intervention study is ongoing with the aim to immunize as many as possible of $\sim 250,000$ persons $\geqslant 65$ yrs of age with both influenza (yearly) and pneumococcal vaccines [37]. This is a nonrandomized, observational, cohort study, where need for admission to hospital for influenza, pneumonia overall, pneumococcal pneumonia and invasive pneumococcal disease will be compared between immunized and nonimmunized patients. The immunized patients personal-identification code is entered into a database and then matched with the four main end-point discharge diagnoses, according to the International Classification of Diseases, Tenth Revision (ICD-10-CM), from all hospitals in Stockholm County. In the first study year (1998), 100,242 persons ( $39 \%$ of the target population) received the influenza vaccine $(n=99,401)$ and/or the pneumococcal vaccine $(n=77,018)$. During the first six-month observation period, December 1998 to May 1999, the incidence of hospital treatment was significantly lower in the vaccinated than in the unvaccinated cohort for all end-points; 46\% lower for influenza, 29\% for pneumonia overall, $46 \%$ for pneumococcal pneumonia and $50 \%$ for invasive pneumococcal disease. These data are promising, but work is now ongoing to address some crucial questions, the most important being the comparability of the vaccinated and unvaccinated groups, but also, of course, the outcome during influenza-free periods.

Invasive pneumococcal disease. In contrast to pneumonia, there is strong evidence that the polysaccharide vaccine is effective in preventing invasive pneumococcal disease. In young adults and adults of mixed ages, the prospective trials using a 13- or 14 -valent vaccine performed during the 1970s in South Africa and Papua New Guinea, showed $\sim 80 \%$ effectiveness in prevention of bacteraemia or bacteraemic pneumonia [21, 23]. A meta-analysis of nine prospective studies, including 40,431 patients, performed during 1966-1987, confirmed these findings and concluded that the vaccine is efficacious in the prevention of bacteraemic pneumonia among lowrisk adults, defined as $<55$ yrs of age and healthy [30]. Effectiveness in case-control studies and indirect cohort studies, also including elderly persons, have generally ranged from $\sim 50-80 \%[19,20$, 38-40] (table 2). The only exception [38] may be explained by a relatively small sample size and an incomplete ascertainement of vaccination status of patients. Interestingly, a similar protective efficacy, $60-80 \%$, in prevention of invasive pneumococcal disease in the elderly was found in two of the most recent prospective trials, although in both studies, the number of patients with bacteraemia was too small to obtain a statistical significance [17, 27]. In the Swedish study there were five bacteraemic patients in the control group versus one in the vaccine group, and the corresponding figures in the Finnish trial were five versus two patients, respectively.

The indirect cohort study from the Centers for Disease Control (CDC) [20] indicated that the vaccine may also be effective in patients with underlying immunocompromising diseases (table 2). However, these results were based on the fact that patients with different diseases were grouped together. Since the number of patients in each category was small, the 
Table 2.-Case-control and indirect cohort studies of pneumococcal vaccine effectiveness in prevention of invasive disease

\begin{tabular}{|c|c|c|c|c|c|}
\hline Reference & Population studied & $\begin{array}{c}\text { Case/ } \\
\text { controls } \\
\mathrm{n}\end{array}$ & Study design & Type of infection & $\begin{array}{l}\% \text { Efficacy or } \\
\text { effectiveness* } \\
(95 \% \mathrm{CI})\end{array}$ \\
\hline$[38]$ & $\begin{array}{l}\text { Patients admitted to a Veterans } \\
\text { Administration Centre }\end{array}$ & $89 / 89$ & Case-control & Bacteraemia & $-21(-221-55)$ \\
\hline [39] & $\begin{array}{l}\text { Patients }>55 \text { yrs of age } \\
\text { admitted to hospital }\end{array}$ & $122 / 244$ & Case-control & Invasive infection $^{\#}$ & $70(37-86)$ \\
\hline [19] & $\begin{array}{l}\text { Patients } \geqslant 18 \text { yrs of age } \\
\text { admitted to hospital }\end{array}$ & $983 / 983$ & Case-control & $\begin{array}{l}\text { Invasive infection } \\
\text { All patients } \\
\text { Immunocompetent patients } \\
\text { Immunocomopromized patients } \\
\text { Persons aged 65-74 yrs }(\mathrm{yr}<3)^{\oplus} \\
\text { Persons aged 65-74 yrs }(\mathrm{yr} 3-5)^{+} \\
\text {Persons aged 65-74 yrs }(\mathrm{yr}>5)^{\$} \\
\text { Persons aged 75-84 yrs }(\mathrm{yr}<3)^{\oplus} \\
\text { Persons aged 75-84 yrs }(\mathrm{yr} 3-5)^{+} \\
\text {Persons aged } \geqslant 85 \mathrm{yrs}(\mathrm{yr}<3)^{+}\end{array}$ & $\begin{array}{l}56(42-67) \\
61(47-72) \\
21(-55-60) \\
80(51-92) \\
71(30-88) \\
58(-2-83) \\
67(20-87) \\
53(-15-81) \\
46(-31-78)\end{array}$ \\
\hline$[20]$ & $\begin{array}{l}\text { Patients }>5 \text { yrs of age } \\
\text { with pneumococcal } \\
\text { bacteraemia or meningitis }\end{array}$ & $515 / 2322$ & Indirect cohort & $\begin{array}{l}\text { Bacteraemia and/or meningitis } \\
\text { All patients } \\
\text { Moderate risk patients } f \\
\text { High risk patients** } \\
\text { Patients aged } \geqslant 65 \mathrm{yrs}\end{array}$ & $\begin{array}{l}57(45-66) \\
49(23-65) \\
49(22-67) \\
75(57-85)\end{array}$ \\
\hline [40] & $\begin{array}{l}\text { Patients } \geqslant 2 \text { yrs of age } \\
\text { with a chronic illness, or } \\
\geqslant 65 \text { yrs of age }\end{array}$ & $85 / 152$ & Case-control & Bacteraemia & $81(34-94)$ \\
\hline
\end{tabular}

*: For prevention of infection with serotype included in the vaccine; ${ }^{*}$ : isolation of Streptococcus pneumoniae from a normally sterile site; ${ }^{\Uparrow}$ : efficacy during the first three after vaccination; ${ }^{+}$: efficacy during yr $3-5$ after vaccination; ${ }^{\$}$ : efficacy during yr $>5$ yrs after vaccination; ${ }^{f}$ : including persons $>5$ yrs of age with chronic, but not immunocompromizing illnesses, and those aged 65 yrs or more without underlying illness; **: including sickle-cell anaemia, anatomic asplenia, dysgammaglobulinaemia, haematological, and several other immunocompromizing conditions. CI: confidence interval.

CI became very large and included zero for most of the diseases when analysed separately.

The question of the protective efficacy of the polysaccharide vaccine in the prevention of invasive disease in children is unresolved [3]. The case-definition of two of the case-control and indirect cohort studies included small children, although it was not clear how many, if any children were included [20, 40]. With the exception of a study in Papua New Guinea, indicating that the vaccine is also efficacious in children $<2$-yrs-old [41], this field has been poorly explored. However, an indirect cohort analysis of invasive pneumococcal disease in 48 vaccinated and 125 unvaccinated children, $2-5$ yrs of age, with an underlying chronic disease, was recently published [42]. This study showed an overall effectiveness of the vaccine of $63 \%(95 \% \mathrm{CI}, 8-85 \%)$. If only serotypes not included in the heptavalent conjugate vaccine (see later) were included in the analysis, the effectiveness was as high as 94\% (95\% CI, 45-100\%). One reason for the low interest in polysaccharide vaccine in children has probably been the ongoing development of the new protein-conjugate vaccines [3]. However, the high vaccine price and need of repeated doses are likely to make an extensive global use of the conjugate vaccines very difficult. This, together with the limited number of serotypes that, at the moment, are technically possible to include in the conjugate vaccines, creates a strong argument for re-evaluation of the polysaccharide vaccine in children.

In patients with human immunodeficiency virus
(HIV) infection, S. pneumoniae is the most commonly identified bacterial pathogen causing pneumonia, and this patient group have a 10-100 times higher risk for pneumococcal pneumonia and bacteraemia than nonHIV infected persons [43-47]. In communities with a high prevalence of HIV infection, the large percentage of patients with pneumococcal disease may be attributable to the number of patients who are HIVpositive $[48,49]$. Despite the higher risk, the mortality in invasive pneumococcal disease does not seem to be higher in infected than in non-HIV infected persons, which may be due to the fact that the former are often young, do not have other underlying diseases, and receive prompt attention by medical care [46, 47, 50]. Conflicting results have been obtained concerning the immunogenicity of the pneumococcal polysaccharide vaccine in HIV infected patients. However, HIVpositive patients seem to respond less well to vaccination than healthy adults, at least for some serotypes, whereas it is unclear if there is a correlation between the magnitude of the response and the patients CD4+ T-cell counts [51, 52]. So far there are few data concerning the efficacy of the polysaccharide vaccine in HIV-positive patients. A recent double-blind, randomized, placebo-controlled clinical trial showed that the vaccine was ineffective in 1,392 HIV-1 infected Ugandan adults, aged 15-55 yrs [53]. In fact, all-cause pneumonia was significantly more frequent in the vaccinated group, which made the authors speculate whether the vaccine might even have been harmful in this population. In slight contrast to this, a 
retrospective case-control study performed in the USA demonstrated protection against invasive pneumococcal infections among White but not Black HIVinfected adults [54].

Adverse reactions, duration of antibodies and revaccination. The pneumococcal polysaccharide is a safe vaccine [1]. Although mild local reactions usually lasting $<48 \mathrm{~h}$ are common, moderately severe systemic reactions such as fever and myalgias are uncommon, and severe systemic reactions, for example anaphylaxia, are extremely rare $[1,30,55]$.

Following vaccination there is a slow but steady decline of serotype-specific antibody titres and prevaccination levels are generally reached within 5-10 yrs $[1,56,57]$, although the rate of this decline varies and may be more rapid in some groups, for example the elderly [58]. Since the polysaccharide vaccine is T-cellindependent, an anamnestic response does not occur at revaccination, but there is a significant increase in antibody levels, albeit sometimes to a slightly lower level than after the primary dose [59].

To the present author's knowledge, there are no studies on the clinical effectiveness of the polysaccharide vaccine following revaccination. This lack of knowledge, which is basically a lack of knowledge concerning serologic correlates of protection, is probably partly the reason why revaccination has not been commonly advocated. However, a more important reason may have been the fear of an increased risk of adverse reactions. Earlier studies of revaccination have shown an increased risk of severe local reactions of the arthus-type in patients receiving their second dose $<2$ yrs after the first one, while no such increase was seen if the second dose was given after $\geqslant 4$ yrs [1]. These findings seem logical, since the level of prevaccination antibodies in patients receiving their first dose have been shown to be associated with the risk for both local and general adverse events [60]. However, a recent comparative intervention study of adverse reactions in persons $50-74$ yrs of age receiving their first pneumococcal vaccination $(\mathrm{n}=901)$ versus those who were revaccinated $(n=513), \geqslant 5$ yrs after a primary dose, has clarified that prevaccination antibody levels are much more important than the time period that has elapsed after vaccination [61]. No serious or unexpected adverse events occurred and systemic symptoms were equally rare (e.g. fever $\geqslant 38.6^{\circ} \mathrm{C}, 0.4-1 \%$ ) in the two groups. However, the risk of a local reaction of more than $10.2 \mathrm{~cm}$ in diameter within two days of vaccination was significantly higher in revaccinated persons $(11 \%)$ than in those receiving their first dose $(3 \%)$. These reactions resolved by a median of 3 days following vaccination. This increased risk was seen in immunocompetent but not immunocompromised persons. The risk of local reactions was significantly correlated with the prevaccination antibody concentrations, irrespective of whether it was a primary or revaccination. Interestingly, in immunocompetent persons who were revaccinated, the risk of adverse events was not correlated with the number of years since first vaccination, only to prevaccination antibody concentrations, thus illustrating that the rate of decline of antibody levels varies from person to person.

In conclusion, following revaccination there is no increased risk of severe systemic reactions than after the primary dose, only for relatively mild local ones. Thus, the risk of adverse events does not represent a contraindication for a single revaccination.

One problem which may be encountered is which patient groups should be revaccinated and when. According to the recommendations of the Advisory Committee on Immunization Practices (ACIP) in the USA this is a complicated question [1]. ACIP states that routine revaccination of immunocompetent persons is not recommended. Revaccination is only recommended in those $>2$ yrs of age who are at highest risk of serious pneumococcal infection and are likely to have a rapid decline of antibody levels, provided that 5 yrs have elapsed after the first dose. This latter group includes patients with asplenia, HIV infection or other immunocompromising diseases or treatments. Further, revaccination of persons $\geqslant 65 \mathrm{yrs}$ of age is only recommended if they received their first dose $\geqslant 5$ yrs previously and before the age of 65 yrs. The author believes the ACIP recommendations to be unnecessarily complicated and contradictory to an improved implementation of the vaccine. Given the knowledge of the steady antibody decline after vaccination, the low risk of adverse events following revaccination and the low cost of the polysaccharide vaccine, it would be logical to recommend revaccination to all patient groups where the primary vaccination is recommended. If the increased risk of adverse events in immunocompetent persons is a concern, revaccination could, in this group, be performed after $\sim 10$ yrs, by which time it is likely that most persons have reached their prevaccination antibody levels. Further, the study of SHAPIRO et al. [19] showed that the significant protection against invasive disease in the elderly vaccinated with the pneumococcal vaccine, lasted $<5$ yrs for those immunized between $65-74$ yrs, and $<3$ yrs for those immunized between 75-84 yrs (table 2). Why then, should an elderly person who received a primary vaccination at the age of, for example, 66 yrs, not be revaccinated?

The question of whether vaccination with the polysaccharide vaccine should be repeated more than once remains unanswered. Very little is known about the immune response and safety following repeated revaccinations.

\section{Conjugate vaccines}

Immunogenicity. In contrast to pure polysaccharide antigens, polysaccharide-protein-conjugate vaccines have also been shown to induce antibody production and an immunological memory in very young children with an immature immune system [62,63]. The immune response to protein antigens is T-cell-dependent, so that a covalent coupling of the pneumococcal polysaccharide to a protein carrier induces T-helper cells to stimulate polysaccharide specific B-cells to develop into either antibody producing plasma cells or memory cells. Conjugate vaccines including 7-11 serotypes are 
under evaluation in clinical trials, and a 7-valent vaccine has recently been licensed in some countries. The 7-valent vaccines include serotypes $4,6 \mathrm{~B}, 9 \mathrm{~V}, 14$, $18 \mathrm{C}, 19 \mathrm{~F}, 23 \mathrm{~F}$ and cover $\sim 50-80 \%$ of the serotypes causing invasive pneumococcal infections in children. In the 9-valent and 11-valent vaccines, serotypes 1 and 5 , and 3 and $7 \mathrm{~V}$, respectively, have been added. By these additions a $70-90 \%$ coverage could be achieved in most regions of the world [64]. Several carrier proteins have been used, tetanus toxoid, diphteria toxoid, CRM197 protein and meningococcal outer membrane protein, and although some differences have been shown between these vaccines, concerning, for example, dose-response and avidity, they generally produce a significant antibody response, antibodies with a high functional activity, and prime for memory response in the very young $[62,63,65-68]$. To induce antibody production in early infancy, three doses are needed for some serotypes (6B and $23 \mathrm{~F}$ ), while one dose may be enough for other serotypes $(14,18 \mathrm{C}, 19 \mathrm{~F})$ [62]. The conjugate vaccines have also been shown to produce salivary anticapsular antibodies in infants and reduce nasopharyngeal carriage of pneumococcal serotypes included in the vaccine [62, 69-72]. This reduction of carriage is potentially very important from a clinical point of view, since the pneumococcal serotypes most often associated with penicillin resistance are included in the 7-valent vaccine. However, at the same time, a relative increase in carriage rates of nonvaccine types has been observed, raising some concern that the incidence of infections caused by such types may increase.

Conjugate vaccines also seem to be able to induce an immunoglobulin $\mathrm{G}$ ( $\mathrm{IgG}$ ) response in immunocompromised children infected with HIV [73], and in older children with recurrent infections, and who have not responded to the 23-valent polysaccharide vaccine [74]. In contrast, studies performed with conjugate vaccines in adults have largely been unsuccessful, in that the magnitude of the antibody rise seems to be approximately the same as that following vaccination with the 23-valent polysaccharide vaccine [75-78]. Two probable explanations of this have been proposed [62]; firstly, adults may have high pre-immunization antibody titres due to previous infections, resulting in poor increases, and secondly, the antigen content of each serotype is much lower in the conjugate vaccine (usually $1-5 \mu \mathrm{g} \cdot$ serotype $^{-1}$ ) than in the polysaccharide vaccine $\left(25 \mu \mathrm{g} \cdot\right.$ serotype $\left.^{-1}\right)$. In addition, the functional capacity of the antibodies induced by the conjugate studies, as well as the possibility of obtaining a booster effect by repeated immunizations, has been poorly studied in adults. That repeated vaccination is of potential importance was illustrated by a study of adults genetically incapable of responding to polysaccharide antigens [79]. In five of seven subjects, an excellent IgG response was seen after a series of vaccinations with protein-conjugated polysaccharide vaccines, ending with an octavalent diptheria toxoid preparation. Thus, it is clear that further studies with the conjugate vaccine are warranted in adults.

Safety and efficacy. Two large clinical trials have recently been reported, one from California [6, 80, 81] and one from Finland [82]. Both studies showed that the 7-valent pneumococcal vaccine, containing serotypes $4,6 \mathrm{~B}, 9 \mathrm{~V}, 14,18 \mathrm{C}, 19 \mathrm{~F}, 23 \mathrm{~F}$, conjugated to CRM197, was safe and immunogenic. BLACK et al. [6] studied 37,868 children in Northern California, who were randomly assigned 1:1 to receive either the pneumococcal CRM197-conjugate vaccine or a meningococcal CRM197-conjugate vaccine at 2, 4, 6, and 12-15 months of age. The main end-point was the occurrence of invasive pneumococcal disease caused by vaccine serotype, and other outcomes included pneumonia and otitis media. The vaccine proved to be highly efficacious in the prevention of invasive disease, moderately efficacious in the prevention of pneumonia, and showed a significant, but low-level efficacy in the prevention of clinical visits or episodes of otitis media $[6,81]$ (table 3 ). There were nine cases of invasive disease caused by nonvaccine serotypes, six in the control group (serotypes 3, 6A, 11A, 18B, 19A, 38) and three in the vaccine group (serotype $10 \mathrm{~F}$ and two type 38). Thus, no increase of nonvaccine types in the vaccine group could be demonstrated, even if the vaccine-related types (types 6A, 18B, 19A) were discounted.

In the Finnish study, acute pneumococcal otitis media was verified by myringotomy and bacterial culture [82]. In the double-blind, randomized study, 1,662 children received either the pneumococcalconjugate vaccine or hepatitis B vaccine (control), at 2, 4, 6, and 12 months of age. For all episodes of acute otitis media there was a $6 \%(95 \%$ CI, $-4-16 \%)$ reduction in the vaccine group, as compared to the control group, which, although not statistically significant, was of the same magnitude as in the Californian study. Nearly 700 episodes of pneumococcal otitis media were diagnosed, irrespective of serotype, and in this group the vaccine was 34\% (95\% CI, 21-45\%) efficacious. Serotype-specific pneumococcal otitis media was diagnosed in 107 of 786 children in the vaccine group, compared to 250 of 794 children in the control

Table 3. -Efficacy in 'Intent to treat' analysis of a 7-valent pneumococcal CRM197-conjugate vaccine versus control (meningococcal CRM197-conjugate vaccine) in prevention of invasive pneumococcal disease, pneumonia and otitis media

\begin{tabular}{lrc}
\hline Disease/Infection & $\mathrm{n}$ & Efficacy \\
\hline Invasive disease & & \\
$\quad$ Serotype-specific & 52 & $94(80-99)$ \\
$\quad$ Regardless of serotype & 61 & $89(74-96)$ \\
Pneumonia & & \\
$\quad$ Clinical diagnosis & 1066 & $11(1-21)$ \\
$\quad$ Radiograph verified & 115 & $33(7-52)$ \\
$\quad$ Consolidation* & 26 & $73(38-88)$ \\
Otitis media & 73041 & $8(5-11)$ \\
$\quad$ Visits & 52789 & $6(4-9)$ \\
$\quad$ Episodes & 5451 & $9(4-14)$ \\
$\quad$ Frequent otitis media\# & 432 & $20(4-34)$ \\
$\quad$ Ventilatory tube placement &
\end{tabular}

Data presented as \% (95\% confidence interval). *: Consolidation with a diameter of $\geqslant 2 \mathrm{~cm}$ visible on radiograph; \#: $\geqslant 3$ episodes during 6 months or $\geqslant 4$ episodes during $1 \mathrm{yr}$. CI: confidence interval. Adapted from [6] and [81]. 
group, corresponding to an efficacy of 57\% (95\% CI, 44-67\%). The efficacy against vaccine-related serotypes (types $6 \mathrm{~A}, 9 \mathrm{~N}, 18 \mathrm{~B}, 19 \mathrm{~A}, 23 \mathrm{~A})$ was $51 \%(95 \%$ CI, 27-67\%), while the reverse was seen for all other types, with an increase of $34 \%(95 \%$ CI, $0-81 \%)$ in the vaccine group compared to controls.

Thus, the results so far with the conjugate vaccine in children $<2$ yrs of age have been very promising for invasive disease, severe pneumonia and serotypespecific (and vaccine-related types) otitis media. Although the efficacy of the conjugate vaccine in prevention of otitis media overall seems to be only marginal, it has been estimated that as many as 2 million episodes of this disease could be prevented each year in the USA by a widespread vaccination [6]. However, perhaps the most important potential benefit of the conjugate vaccine is the possibility of preventing carriage and infection with those pneumococcal serotypes mostly associated with antibiotic resistance. Of course, many questions remain; the optimal dosage of the vaccine, the duration of protection, the need for booster doses with the conjugate or the polysaccharide vaccines, if herd immunity can be induced, and if there will be a replacement of nonvaccine types [62]. In addition, the usage of the vaccine in other patient groups, for example immunocompromised patients and elderly persons, needs further study.

Several more trials are ongoing, or in the process of being started, in South Africa [72], among Native Americans in the USA, in the Netherlands, Israel, Chile, the Gambia and the Philippines.

\section{Future prospects of new pneumococcal vaccine formu- lations}

The use of adjuvants is one possible way of improving the immunogenicity of pure polysaccharide antigens, but also of polysaccharides converted to T-cell-dependent forms by protein-conjugation. In mice treated with interleukin-12 (IL-12) and then given pneumococcal polysaccharide vaccine, there is a significantly enhanced response of both $\operatorname{IgG} 2 \mathrm{a}$, the murine isotype most efficient in mediating complement fixation and opsonization, and IgG3 [83]. This cytokine has also been shown to enhance cellmediated immunity through the activation of $\mathrm{T}$ and natural killer (NK) cells. These results suggests that IL-12 might also be useful as an adjuvant to increase the protective efficacy of the pneumococcal vaccine in humans. However, the results from a recent phase I/II randomized, double-blind study were disappointing [84]. Co-administration of $1 \mu \mathrm{g}$ or $4 \mu \mathrm{g}$ of recombinant human IL-12 (rh-IL-12) compared to placebo (23-valent pneumococcal vaccine alone), did not significantly increase total IgG or antibody isotype concentrations nor the antibody avidity, but was associated with high incidence of both local and systemic side-effects. During the last decade, a lot of work has been done to develop vaccines against protein antigens common for all pneumococcal serotypes. The most studied so far is the surface protein A (PspA) [85]. This molecule is highly immunogenic and antibodies to PspA have been shown to protect against pneumococcal infections in mice [86-88]. A recent study demonstrated that antibodies to PspA are present in human sera, both in adults and children [89]. Children 7-36 months of age with invasive pneumococcal infection, had significantly lower antibody levels than those with other infections, indicating that PspA antibodies might play a role in protection against pneumococcal disease. Other possible protein vaccine candidates are pneumococcal surface adhesin A (psaA), choline-binding protein A (cbpA), and $S$. pneumoniae secretory immunoglobulin-A (IgA) binding protein (SpsA), proteins all probably involved in the process of bacterial adherence [90-92], and further, two proteins of importance for the virulence of the bacteria, pneumolysin [93] and neuramidase [85]. However, no large trials have been performed in humans with any of these vaccine candidates, and their potential usefulness in clinical practice remains unknown.

\section{Cost-effectiveness of pneumococcal vaccination}

Previous studies on the cost-effectiveness of vaccination with the pneumococcal polysaccharide vaccine have been hampered by the incorrect assumption that the efficacy of the vaccine in prevention of pneumonia in the elderly is of the same magnitude as that of invasive disease $[94,95]$. However, in a study from the USA, the vaccine was shown to be highly costeffective and, in most instances, cost-saving in the prevention of pneumococcal bacteraemia in persons $\geqslant 65$ yrs of age [96]. Because of differences between the USA and countries in western Europe regarding the organization and costs of healthcare, a similar European multicentre study was performed in Belgium, France, Scotland, Spain and Sweden [97]. This study also demonstrated that the vaccine was costeffective, although only to an acceptable to moderate degree, in preventing invasive disease in the elderly. The main reasons for the more favourable results in the American study, were that they assumed a higher incidence of invasive disease, lower vaccine costs, and higher hospitalization costs, than in the European study. A cost-effectiveness study of the pneumococcal conjugate vaccine has also been performed, based on the effectiveness data from the Californian study [6, 81]. The results of this study indicate that the newly licensed heptavalent conjugate vaccine may have the potential to be cost-effective in the prevention of invasive disease, pneumonia and otitis media, and could result in net savings for society if the vaccine cost was $<\$ 46$ per dose [98].

\section{Conclusions}

The global health burden of pneumococcal diseases creates an urgent need for an effective vaccine. The effectiveness of the 23-valent polysaccharide vaccine in the prevention of pneumonia is unclear, but it is definitely efficacious and cost-effective in the prevention of invasive pneumococcal disease in immunocompetent persons, including the elderly, and may 
also be effective in some groups of immunocompromised patients. The polysaccharide vaccine is, therefore, highly recommended in persons $\geqslant 2 \mathrm{yrs}$ of age, who have a high risk for pneumococcal disease, and in all older ( $\geqslant 55-65$ yrs of age) adults. One revaccination, after 5 yrs have elapsed after the first dose, can be safely performed and is recommended in all persons who fulfilled the indications for primary vaccination. Polysaccharide-protein-conjugate vaccines are effective in the prevention of invasive disease, severe pneumonia and serotype-specific (and vaccinerelated types) otitis media in children $<2$ yrs of age, and may be an effective tool in limiting the spread of antibiotic resistant pneumococci. The conjugate vaccines can be recommended primarily in countries where the coverage of included serotypes is high, or where there is a substantial clinical problem with penicillin-resistant pneumococci. A low serotype coverage, the need for repeated doses, and a high price, may decrease the usefulness of the new conjugate vaccines in many countries. The efficacy of the 23-valent polysaccharide vaccines in the prevention of invasive disease in young children should, therefore, be reevaluated. The optimal usage of conjugate vaccines is still largely unknown, and hopefully questions concerning the duration of protection, need for booster doses, herd immunity, and the risk for replacement of nonvaccine types, will be answered by ongoing studies. In addition, the usage of the conjugates in other patient groups, for example immunocompromised and elderly patients, needs further study. Finally, the "ideal" pneumococcal vaccine, probably based on a protein antigen common to all serotypes, that is safe and highly immunogenic in all age groups and also in immucompromised persons is still awaited. However, don't forget to use the current vaccines while waiting!

\section{References}

1. Anonymous. Prevention of pneumococcal disease. MMWR Morbid Mortal Weekly Rep 1997; 46: 1-24.

2. Anonymous. Pneumococcal vaccines. WHO position paper. Wkly Epidemiol Rec 1999; 74: 177-183.

3. Mulholland K. Strategies for the control of pneumococcal diseases. Vaccine 1999; 17: Suppl. 1, S79-84.

4. Fedson DS, Scott JAG. The burden of pneumococcal disease among adults in developed and developing countries: what is known and what is not known. Vaccine 1999; 17: S11-S18.

5. Honkanen PO, Mäkelä PH. Pneumococcal vaccination in the elderly. BioDrugs 1999; 12: 19-25.

6. Black S, Shinefield H, Fireman B, et al. Efficacy, safety and immunogenicity of heptavalent pneumococcal conjugate vaccine in children. Northern California Kaiser Permanente Vaccine Study Center Group. Pediatr Infect Dis $J$ 2000; 19: 187-195.

7. Kalin ME, Örtqvist $\AA$, Almela M, et al. Prospective study of prognostic factors in community-acquired bacteremic pneumococcal disease in five countries. $J$ Infect Dis 2000; 182: 840-847.

8. Butler JC, Shapiro ED, Carlone GM. Pneumococcal vaccines: history, current status, and future directions. Am J Med 1999; 107: 69S-76S.

9. Austrian R, Gold J. Pneumococcal bacteremia with especial reference to bacteremic pneumococcal pneumonia. Ann Intern Med 1964; 60: 759-776.

10. Henrichsen J. Six newly recognized types of Streptococcus pneumoniae. J Clin Microbiol 1995; 33: 2759 2762.

11. Musher DM, Luchi MJ, Watson DA, Hamilton R, Baughn RE. Pneumococcal polysaccharide vaccine in young adults and older bronchitics: determination of $\mathrm{IgG}$ responses by ELISA and the effect of adsorption of serum with non-type-specific cell wall polysaccharide. J Infect Dis 1990; 161: 728-735.

12. Hedlund JU, Kalin ME, Örtqvist ÅB, Henrichsen J. Antibody response to pneumococcal vaccine in middle-aged and elderly patients recently treated for pneumonia. Arch Intern Med 1994; 154: 1961-1965.

13. Sankilampi U, Honkanen PO, Bloigu A, Herva E, Leinonen M. Antibody response to pneumococcal capsular polysaccharide vaccine in the elderly. $J$ Infect Dis 1996; 173: 387-393.

14. Rubins JB, Puri AK, Loch J, et al. Magnitude, duration, quality, and function of pneumococcal vaccine responses in elderly adults. J Infect Dis 1998; 178: 431-440.

15. Rubins JB, Alter M, Loch J, Janoff EN. Determination of antibody responses of elderly adults to all 23 capsular polysaccharides after pneumococcal vaccination. Infect Immun 1999; 67: 5979-5984.

16. Romero-Steiner S, Musher DM, Cetron MS, et al. Reduction in functional antibody activity against Streptococcus pneumoniae in vaccinated elderly individuals highly correlates with decreased IgG antibody avidity. Clin Infect Dis 1999; 29: 281-288.

17. Örtqvist Å, Hedlund J, Burman LA, et al. Randomised trial of 23-valent pneumococcal capsular polysaccharide vaccine in prevention of pneumonia in middle-aged and elderly people. Swedish Pneumococcal Vaccination Study Group. Lancet 1998; 351: 399 403.

18. Clemens JD, Shapiro ED. Resolving the pneumococcal vaccine controversy: are there alternatives to randomized clinical trials? Rev Infect Dis 1984; 6: 589600.

19. Shapiro ED, Berg AT, Austrian R, et al. The protective efficacy of polyvalent pneumococcal polysaccharide vaccine. $N$ Engl J Med 1991; 325: 14531460.

20. Butler JC, Breiman RF, Campbell JF, Lipman HB, Broome CV, Facklam RR. Pneumococcal polysaccharide vaccine efficacy. An evaluation of current recommendations. JAMA 1993; 270: 1826-1831.

21. Austrian R, Douglas RM, Schiffman G, et al. Prevention of pneumococcal pneumonia by vaccination. Trans Assoc Am Physicians 1976; 89: 184-194.

22. Smit P, Oberholzer D, Hayden-Smith S, Koornhof HJ, Hilleman MR. Protective efficacy of pneumococcal polysaccharide vaccines. JAMA 1977; 238: 2613 2616.

23. Riley ID, Tarr PI, Andrews M, et al. Immunisation with a polyvalent pneumococcal vaccine. Reduction of adult respiratory mortality in a New Guinea Highlands community. Lancet 1977; 1: 1338-1341.

24. Gaillat J, Zmirou D, Mallaret MR, et al. Essai clinique du vaccin antipneumococcique chez personnes agées vivant en institution. Rev Epidemiol Sante Publique 1985; 33: 437-444.

25. Koivula I, Sten M, Leinonen M, Makela PH. Clinical efficacy of pneumococcal vaccine in the elderly: a 
randomized, single-blind population-based trial. $\mathrm{Am}$ J Med 1997; 103: 281-290.

26. Simberkoff MS, Cross AP, Al-Ibrahim M, et al. Efficacy of pneumococcal vaccine in high-risk patients. Results of a Veterans Administration Cooperative Study. N Engl J Med 1986; 315: 1318-1327.

27. Honkanen PO, Keistinen $\mathrm{T}$, Miettinen $\mathrm{L}$, et al. Incremental effectiveness of pneumococcal vaccine on simultaneously administered influenza vaccine in preventing pneumonia and pneumococcal pneumonia among persons aged 65 years or older. Vaccine 1999; 17: 2493-2500.

28. Hedlund JU, Örtqvist BÅ, Kalin ME, Scalia-Tomba $\mathrm{G}$, Giesecke J. Risk of pneumonia in patients previously treated in hospital for pneumonia. Lancet 1992; 340: 396-397.

29. Hedlund J, Örtavist Å, Konradssen HB, Kalin M. Recurrence of pneumonia in relation to the antibody response after pneumococcal vaccination in middleaged and elderly adults. Scand J Infect Dis 2000; 32: 281-286.

30. Fine MJ, Smith MA, Carson CA, et al. Efficacy of pneumococcal vaccination in adults. A meta-analysis of randomized controlled trials. Arch Intern Med 1994; 154: 2666-2677.

31. Hutchison BG, Oxman AD, Shannon HS, Lloyd S, Altmayer CA, Thomas K. Clinical effectiveness of pneumococcal vaccine. Meta-analysis. Can Fam Physician 1999; 45: 2381-2393.

32. Nichol KL, Baken L, Wuorenma J, Nelson A. The health and economic benefits associated with pneumococcal vaccination of elderly persons with chronic lung disease. Arch Intern Med 1999; 159: 2437-2442.

33. Foster DA, Talsma AN, Furumoto-Dawson A, et al. Influenza vaccine effectiveness in preventing hospitalization for pneumonia in the elderly. Am J Epidemiol 1992; 136: 296-307.

34. Fedson DS, Wajda A, Nicol JP, Hammond GW, Kaiser DL, Roos LL. Clinical effectiveness of influenza vaccination in Manitoba. JAMA 1993; 270: 19561961.

35. Mullooly JP, Bennett MD, Hornbrook MC, et al. Influenza vaccination programs for elderly persons: Cost-effectiveness in a health maintenance organization. Ann Intern Med 1994; 121: 947-952.

36. Nichol KL, Margolis KL, Wuorenma J, von Sternberg $T$. The efficacy and cost effectiveness of vaccinations against influenza among elderly persons living in the community. N Engl J Med 1994; 331: 778-784.

37. Christenson B, Lundbergh P, Hedlund J, Örtqvist Å. Effects of a large-scale intervention with influenza and 23 -valent pneumococcal vaccines in adults aged 65 years or older: a prospective study. Lancet 2001; 357 : 1008-1011.

38. Forrester HL, Jahnigen DW, LaForce FM. Inefficacy of pneumococcal vaccine in a high-risk population. Am J Med 1987; 83: 425-430.

39. Sims RV, Steinmann WC, McConville JH, King LR, Zwick WC, Schwartz JS. The clinical effectiveness of pneumococcal vaccine in the elderly. Ann Intern Med 1988; 108: 653-657.

40. Farr BM, Johnston BL, Cobb DK, et al. Preventing pneumococcal bacteremia in patients at risk. Results of a matched case-control study. Arch Intern Med 1995; 155: 2336-2340.

41. Riley ID, Lehmann D, Alpers MP, Marshall TF, Gratten H, Smith D. Pneumococcal vaccine prevents death from acute lower-respiratory-tract infections in Papua New Guinean children. Lancet 1986; 2: 877881.

42. Fiore AE, Levine OS, Elliott JA, Facklam RR, Butler JC. Effectiveness of pneumococcal polysaccharide vaccine for preschool-age children with chronic disease. Emerg Infect Dis 1999; 5: 828-831.

43. Redd SC, Rutherford GW 3rd, Sande MA, et al. The role of human immunodeficiency virus infection in pneumococcal bacteremia in San Francisco residents. J Infect Dis 1990; 162: 1012-1017.

44. Janoff EN, Breiman RF, Daley CL, Hopewell PC. Pneumococcal disease during HIV infection. Epidemiologic, clinical, and immunologic perspectives. Ann Intern Med 1992; 117: 314-324.

45. Garcia-Leoni ME, Moreno S, Rodeno P, Cercenado E, Vincente T, Bouza E. Pneumococcal pneumonia in adult hospitalized patients with the human immunodeficiency virus. Arch Intern Med 1992; 352: 1808 1812.

46. Janoff EN, O'Brien J, Thompson P, et al. Streptococcus pneumoniae colonization, bacteremia, and immune response among persons with human immunodeficiency virus infection. $J$ Infect Dis 1993; 167: 4956.

47. Hirschtick RE, Glassroth J, Jordan MC, et al. Bacterial pneumonia in persons infected with the human immunodeficiency virus. Pulmonary Complications of HIV Infection Study Group. $N$ Engl J Med 1995; 333: 845-851.

48. Nuorti JP, Butler JC, Gelling L, Kool JL, Reingold $\mathrm{AL}$, Vugia DJ. Epidemiologic relation between HIV and invasive pneumococcal disease in San Francisco County, California. Ann Intern Med 2000; 132: 182190.

49. Feldman C, Glatthaar M, Morar R, et al. Bacteremic pneumococcal pneumonia in HIV-seropositive and HIV-seronegative adults. Chest 1999; 116: 107-114.

50. Gilks CF, Ojoo SA, Ojoo JC, et al. Invasive pneumococcal disease in a cohort of predominantly HIV-1 infected female sex-workers in Nairobi, Kenya. Lancet 1996; 347: 718-723.

51. Nielsen H, Kvinesdal B, Benfield TL, Lundgren JD, Konradsen HB. Rapid loss of specific antibodies after pneumococcal vaccination in patients with human immunodeficiency virus-1 infection. Scand J Infect Dis 1998; 30: 597-601.

52. Kroon FP, van Dissel JT, Ravensbergen E, Nibbering $\mathrm{PH}$, van Furth R. Antibodies against pneumococcal polysaccharides after vaccination in HIV-infected individuals: 5-year follow-up of antibody concentrations. Vaccine 2000; 18: 524-530.

53. French N, Nakiyingi J, Carpenter LM, et al. 23-valent pneumococcal polysaccharide vaccine in HIV-1 infected Ugandan adults: double-blind, randomised and placebo-controlled trial. Lancet 2000; 355: 2106-2111.

54. Breiman RF, Keller DW, Phelan MA, et al. Evaluation of effectiveness of the 23-valent pneumococcal capsular polysaccharide vaccine for HIV-infected patients. Arch Intern Med 2000; 160: 2633-2638.

55. Honkanen PO, Keistinen T, Kivela SL. Reactions following administration of influenza vaccine alone or with pneumococcal vaccine to the elderly. Arch Intern Med 1996; 156: 205-208.

56. Mufson MA, Krause HE, Schiffman G. Long-term persistence of antibody following immunization with 
pneumococcal polysaccharide vaccine. Proc Soc Exp Biol Med 1983; 173: 270-275.

57. Mufson MA, Krause HE, Schiffman G, Hughey DF. Pneumococcal antibody levels one decade after immunization of healthy adults. Am J Med Sci 1987; 293: 279-284

58. Sankilampi U, Honkanen PO, Bloigu A, Leinonen M. Persistence of antibodies to pneumococcal capsular polysaccharide vaccine in the elderly. $J$ Infect $D$ is 1997; 176: 1100-1104.

59. Mufson MA, Hughey DF, Turner CE, Schiffman G. Revaccination with pneumococcal vaccine of elderly persons 6 years after primary vaccination. Vaccine 1991; 9: 403-407.

60. Sankilampi U, Honkanen PO, Pyhala R, Leinonen M. Associations of prevaccination antibody levels with adverse reactions to pneumococcal and influenza vaccines administered simultaneously in the elderly. Vaccine 1997; 15: 1133-1137.

61. Jackson LA, Benson P, Sneller VP, et al. Safety of revaccination with pneumococcal polysaccharide vaccine. JAMA 1999; 281: 243-248.

62. Eskola J, Anttila M. Pneumococcal conjugate vaccines. Pediatr Infect Dis J 1999; 18: 543-551.

63. Goldblatt D. Conjugate vaccines. Clin Exp Immunol 2000; 119: 1-3.

64. Hausdorff WP, Bryant J, Kloek C, Paradiso PR, Siber GR. The contribution of specific pneumococcal serogroups to different disease manifestations: implications for conjugate vaccine formulation and use, part II. Clin Infect Dis 2000; 30: 122-140.

65. Anttila M, Eskola J, Ahman H, Kayhty H. Avidity of $\mathrm{IgG}$ for Streptococcus pneumoniae type $6 \mathrm{~B}$ and $23 \mathrm{~F}$ polysaccharides in infants primed with pneumococcal conjugates and boosted with polysaccharide or conjugate vaccines. J Infect Dis 1998; 177: 1614-1621.

66. Ahman H, Kayhty $\mathrm{H}$, Lehtonen $\mathrm{H}$, Leroy $\mathrm{O}$, Froeschle J, Eskola J. Streptococcus pneumoniae capsular polysaccharide-diphtheria toxoid conjugate vaccine is immunogenic in early infancy and able to induce immunologic memory. Pediatr Infect Dis $J$ 1998; 17: 211-216.

67. Ahman H, Kayhty H, Vuorela A, Leroy O, Eskola J. Dose dependency of antibody response in infants and children to pneumococcal polysaccharides conjugated to tetanus toxoid. Vaccine 1999; 17: 2726-2732.

68. Anttila M, Eskola J, Ahman H, Kayhty H. Differences in the avidity of antibodies evoked by four different pneumococcal conjugate vaccines in early childhood. Vaccine 1999; 17: 1970-1977.

69. Dagan R, Melamed R, Muallem M, et al. Reduction of nasopharyngeal carriage of pneumococci during the second year of life by a heptavalent conjugate pneumococcal vaccine. J Infect Dis 1996; 174: 1271-1278.

70. Dagan R, Muallem M, Melamed R, Leroy O, Yagupsky P. Reduction of pneumococcal nasopharyngeal carriage in early infancy after immunization with tetravalent pneumococcal vaccines conjugated to either tetanus toxoid or diphtheria toxoid. Pediatr Infect Dis $J$ 1997; 16: 1060-1064.

71. Korkeila M, Lehtonen H, Ahman H, Leroy O, Eskola J, Kayhty H. Salivary anti-capsular antibodies in infants and children immunised with Streptococcus pneumoniae capsular polysaccharides conjugated to diphtheria or tetanus toxoid. Vaccine 2000; 18: 1218 1226.

72. Mbelle N, Huebner RE, Wasas AD, Kimura A,
Chang I, Klugman KP. Immunogenicity and impact on nasopharyngeal carriage of a nonavalent pneumococcal conjugate vaccine. J Infect Dis 1999; 180: 11711176.

73. King JC Jr, Vink PE, Farley JJ, Smilie M, Parks M, Lichenstein R. Safety and immunogenicity of three doses of a five-valent pneumococcal conjugate vaccine in children younger than two years with and without human immunodeficiency virus infection. Pediatrics 1997; 99: 575-580.

74. Sorensen RU, Leiva LE, Javier FCIII, et al. Influence of age on the response to Streptococcus pneumoniae vaccine in patients with recurrent infections and normal immunoglobulin concentrations. $J$ Allergy Clin Immunol 1998; 102: 215-221.

75. Molrine DC, George S, Tarbell N, et al. Antibody responses to polysaccharide and polysaccharideconjugate vaccines after treatment of Hodgkin disease. Ann Intern Med 1995; 123: 828-834.

76. Powers DC, Anderson EL, Lottenbach K, Mink CM. Reactogenicity and immunogenicity of a proteinconjugated pneumococcal oligosaccharide vaccine in older adults. J Infect Dis 1996; 173: 1014-1018.

77. Ahmed F, Steinhoff MC, Rodriguez-Barradas MC, Hamilton RG, Musher DM, Nelson KE. Effect of human immunodeficiency virus type 1 infection on the antibody response to a glycoprotein conjugate pneumococcal vaccine: results from a randomized trial. J Infect Dis 1996; 173: 83-90.

78. Chan CY, Molrine DC, George S, et al. Pneumococcal conjugate vaccine primes for antibody responses to polysaccharide pneumococcal vaccine after treatment of Hodgkin's disease. J Infect Dis 1996; 173: 256-258.

79. Musher DM, Groover JE, Watson DA, RodriguezBarradas MC, Baughn RE. IgG responses to proteinconjugated pneumococcal capsular polysaccharides in persons who are genetically incapable of responding to unconjugated polysaccharides. Clin Infect Dis 1998; 27: 1487-1490.

80. Shinefield HR, Black S, Ray P, et al. Safety and immunogenicity of heptavalent pneumococcal CRM197 conjugate vaccine in infants and toddlers. Pediatr Infect Dis $J$ 1999; 18: 757-763.

81. Black S, Shinefield H, Fireman B, et al. Efficacy of heptavalent conjugate pneumococcal vassine in 37,000 infants and children: impact on pneumonia, otitis media, and an update on invasive disease - results of extended follow-up of the efficacy trial cohort. 2nd International Symposium on Pneumococci and Pneumococcal diseases, Sun City, South Africa, March 1923. 2000, 019.

82. Eskola J, Kilpi T, Palma A, et al. Efficacy of a pneumococcal conjugate vaccine against acute otitis media. N Engl J Med 2001; 344: 403-409.

83. Buchanan RM, Arulanandam BP, Metzger DW. IL-12 enhances antibody responses to $\mathrm{T}$-independent polysaccharide vaccines in the absence of $\mathrm{T}$ and NK cells. J Immunol 1998; 161: 5525-5533.

84. Hedlund J, Örtqvist $\AA$, Langer B, Konradsen HB. Safety and efficacy of s.c. recombinant human interleukin12 administered with i.m. pneumococcal polysaccharide vaccine in adults aged 55-65 years. 2nd International Symposium on Pneumococci and Pneumococcal Diseases, Sun City, South Africa, March 19-23. 2000, P21.

85. Paton JC, Berry AM, Lock RA. Molecular analysis of 
putative pneumococcal virulence proteins. Microbial Drug Resist 1997; 3: 1-10.

86. Briles DE, Tart RC, Wu HY, Ralph BA, Russel MW, McDaniel LS. Systemic and mucosal protective immunity to pneumococcal surface protein A. Ann NY Acad Sci 1996; 797: 118-126.

87. Wu HY, Nahm MH, Guo Y, Russel MW, Briles DE. Intranasal immunization of mice with PspA (pneumococcal surface protein A) can prevent intranasal carriage, pulmonary infection, and sepsis with Streptococcus pneumoniae. J Infect Dis 1997; 175: 839-846.

88. Nayak AR, Tinge RC, MacDaniel LS, Briles DE, Curtis R. A live recombinant avirulent oral Salmonella vaccine expressing pneumococcal surface protein A induces protective responses against Streptococcus pneumoniae. Infect Immun 1998; 66: 3744-3751.

89. Virolainen A, Russell W, Crain MJ, Rapola S, Kayhty $\mathrm{H}$, Briles DE. Human antibodies to pneumococcal surface protein A in health and disease. Pediatr Infect Dis $J$ 2000; 19: 134-138.

90. Sampson JS, O'Connor SP, Stinson AR, Tharpe JA, Russel $\mathrm{H}$. Cloning and nucleotide sequence analysis of psaA, the Streptococcus pneumoniae gene encoding a 37-kilodalton protein homologous to previously reported Streptococcus sp. Adhesins. Infect Immun 1994; 62: 319-324.

91. Hammerschmidt S, Talay SR, Brandtzaeg P, Chhatwal GS. SpsA, a novel pneumococcal surface protein with specific binding to secretory immunoglobulin $\mathrm{A}$ and secretory component. Mol Microbiol 1997; 25: 11131124.

92. Rosenow C, Ryan P, Weiser JN, et al. Contribution of novel choline-binding proteins to adherence, colonization and immunogenicity of Streptococcus pneumoniae. Mol Microbiol 1997; 25: 819-828.

93. Rubins JB, Charbonneau D, Paton JC, Mitchell TJ, Andrew PW. Dual function of pneumolysin in the early pathogenesis of murine pneumococcal pneumonia. J Clin Invest 1995; 95: 142-150.

94. Sisk JE, Riegelman RK. Cost effectiveness of vaccination against pneumococcal pneumonia: an update. Ann Intern Med 1986; 104: 79-86.

95. Baltussen RMPM, Ament AJHA, Leidl RM, Rubio C, van Furth R. Cost-effectiveness of vaccination against pneumococcal pneumonia in The Netherlands. Eur J Publ Health 1997; 7: 153-161.

96. Sisk JE, Moskowitz AJ, Whang W, et al. Costeffectiveness of vaccination against pneumococcal bacteremia among elderly people. JAMA 1997; 278: 1333-1339.

97. Ament A, Baltussen R, Duru G, et al. The costeffectiveness of pneumococcal vaccination for older people: A study in five Western European coutries. Clin Infect Dis 2000; 31: 444450.

98. Lieu TA, Ray GT, Black SB, et al. Projected costeffectiveness of pneumococcal conjugate vaccination of healthy infants and young children. JAMA 2000; 283: $1460-1468$. 